\title{
BUILDING INFORMATION MODELING INTEGRATED WITH ELECTRONIC COMMERCE MATERIAL PROCUREMENT AND SUPPLIER PERFORMANCE MANAGEMENT SYSTEM
}

\author{
Yali Ren ${ }^{1}$, Mirosław J. Skibniewski ${ }^{2}$, Shaohua Jiang ${ }^{3}$ \\ ${ }^{1}$ Central Reliability Group, Baker Hughes Inc., Houston, TX, USA \\ ${ }^{2}$ Department of Civil \& Environmental Engineering, University of Maryland, College Park, USA \\ ${ }^{3}$ Department of Construction Management, Faculty of Infrastructure Engineering, \\ Dalian University of Technology, Dalian, China \\ E-mails: ${ }^{1}$ yaliren@umd.edu (corresponding author); ${ }^{2}$ mirek@umd.edu; ${ }^{3}$ shaohuajiang@gmail.com \\ Received 09 Dec. 2011; accepted 29 May 2012
}

\begin{abstract}
This paper describes an innovative approach to the integration of Building Information Modeling (BIM) and electronic commerce (e-commerce) in a material procurement process for improved design-construction integration. The paper includes the present applications, benefits, limitations and barriers to e-commerce and BIM in material procurement processes, compares the present commercial BIM based and non-BIM based quantity takeoff and cost estimating software, and identifies potential benefits of integrating BIM and e-commerce software solutions for construction quantity takeoff, cost estimating and procurement processes. The authors propose a framework for integrating BIM for quantity takeoff and cost estimating applications with e-commerce solutions for material procurement and supplier performance evaluation. The paper presents a proposed solution to link BIM-derived data with RS Means unit price cost data to generate accurate cost estimating reports, one weight coefficient-based model to evaluate the performance of material suppliers, and a preliminary version of corresponding BIM-based application integrated with e-commerce software system.
\end{abstract}

Keywords: Building Information Modeling, electronic commerce, supplier performance evaluation, software design and development.

\section{Introduction}

\subsection{Background}

Construction materials typically account for approximate $40 \%$ to $45 \%$ of the total cost in construction industry (Agapiou et al. 1998). Presently, many construction firms in the United States and other places adopt web-based ecommerce systems to communicate directly with material manufacturers, suppliers, agents and application service providers in order to purchase construction materials. E-commerce provides a viable solution for materials procurement using non-traditional method and creates a winwin situation for most construction material transaction participants (Kong et al. 2004). However, serious interoperability problems still hinder further take up of electronic business tools (Mell, Grance 2010). The scope of construction e-procurement systems still has limitation to streamline the workflow during quantity takeoff, estimating, bidding and procurement stages of the preconstruction interactions among suppliers, contractors and designers (Castro-Lacouture et al. 2007).

Building Information Modeling (BIM) is the process of generating and managing building data during its life cycle. Typically, this process utilizes three dimensional, real-time, dynamic building modeling software and covers geometry, spatial relationships, geographic informa- tion, quantities and various other properties to facilitate building design process (Castro-Lacouture et al. 2007). BIM provides one solution that makes material quantity takeoff and cost estimating easier, faster, cheaper and more accurate compared with traditional methods. By using BIM instead of traditional CAD drawings, material takeoffs, counts, and measurements can be generated, revised and updated directly from the design models, which potentially saves time, labor and other costs, and facilitates the collaboration between various participants during material procurement process. BIM integrated with e-commerce software application has a potential to streamline the workflow of material quantity takeoff, estimating, bidding and procurement stages of the preconstruction interactions among various construction participants (Holness 2008). However, few efforts have been directed to the application and usage of BIM in construction material e-procurement process (Grilo, Jardim-Goncalves 2011), and no commercial BIM integrated with e-commerce software system for material quantity takeoff, cost estimating or procurement process has been designed or developed to date by construction software vendors.

Construction material supplier performance evaluation and information management is an important part of material procurement process, and it constitutes the refe- 
rence for selecting appropriate material suppliers in e-awarding workflow. An improved and effective material supplier performance evaluation method is vital for the procurement success and project profits of construction contractors and subcontractors. BIM integrated with e-commerce material system solutions provide one innovative approach and improved way for material procurement process, and supplier performance evaluation model based on BIM integrated with e-commerce material software system solutions will be more accurate and precise. Therefore, it will be useful to incorporate a practical supplier performance evaluation and information management function module in BIM integrated with an e-commerce construction material procurement software system.

\subsection{Research objectives}

The main objective of the development work described in this paper was to propose a BIM application integrated with e-commerce material procurement framework; to present a BIM-based quantity takeoff and cost estimating solution; to design a new supplier performance evaluation model; and to develop a basic BIM application integrated with e-commerce technology-based construction material quantity takeoff, cost estimating, bidding, tendering, award generation, material procurement and supplier performance evaluation software system in order to reduce human labor cost, to streamline the workflow, to improve accuracy and efficiency, and to streamline collaboration and cooperation of all parties involved in these processes.

To achieve the objective of this work, the following research questions were addressed:

1. What are the benefits, limitations and barriers of e-commerce and BIM applications in construction material quantity takeoff, cost estimating and material procurement processes?

2. What is the possibility and the potential benefit for BIM integrated with e-commerce software solutions in construction material quantity, cost estimating and procurement processes?

3. What is a suitable BIM solution integrated with ecommerce framework that could be applicable for material quantity takeoff, cost estimating, material procurement and supplier performance evaluation and information management process?

4. What is a fully applicable BIM solution integrated with e-commerce tools for supplier performance evaluation and information management?

5. How to design and develop a software system for the integration of BIM application and e-commerce tools for material quantity takeoff, cost estimating, material procurement and supplier performance evaluation and information management?

The primary tasks comprise the following aspects:

1. Identify the application, benefit, limitations and barriers of e-commerce and BIM in construction material quantity takeoff, cost estimating and procurement processes;
2. Compare the present commercial BIM based and non BIM-based quantity takeoff and cost estimating software, choose an applicable BIM development platform and a suitable material cost criterion source, and design and develop a BIM-based material quantity takeoff and cost estimating software module to provide more accurate material cost information as a basic cost standard to evaluate the quotes from the future potential suppliers in the bidding, tendering and awarding process;

3. Design and develop an e-commerce based material procurement management system to realize tendering, bid award management, e-invoicing, epayment and transaction history management, supplier evaluation and information management, and project document and information management functions, and material specifications should be described using BIM in project documents;

4. Provide an effective supplier performance evaluation model, design and develop user-friendly performance evaluation and supplier information management interface to provide valuable reference for construction contractors to select and manage potential future material suppliers;

5. Propose the BIM integrated with e-commerce framework in material procurement process and develop an elementary display software system for the integration of BIM and e-commerce in material quantity takeoff, cost estimating, material procurement and supplier performance evaluation and information management process.

\section{Literature review}

\subsection{Electronic commerce in material procurement}

Electronic commerce (e-commerce) is the sharing of business information, maintaining business relationships, and conducting business transactions by means of telecommunications networks. E-commerce includes the sellbuy relationships and transactions between companies, and the corporate processes that support the commerce within individual firms (Zwass 1996). Electronic commerce can be broadly divided into four main categories (Anumba, Ruikar 2002): Business-to-Business (B2B), Business-to-Consumer (B2C), Business-to-Administration (B2A) and Consumer-to-Administration (C2A). B2B e-commerce has been grown rapidly because of the significant diffusion of the Internet Technology since the early 2000's (Grilo, Jardim-Goncalves 2011).

The architecture, engineering, and construction sectors have embraced and adopted the use of electronic collaborative and electronic commerce platforms in material procurement process (Grilo, Jardim-Goncalves 2010). Electronic procurement (e-procurement) emerged from the early adoption of the Internet Technology in business and was linked to the surge of inter-organizational systems, communities, electronic platforms, meeting places, virtual locations, and infrastructures (Grilo, JardimGoncalves 2011). With e-commerce material procurement system, material sellers can upload their product 
information and find out summary information about their customers and transactions. Material information may include the attributes of each type of materials, which may include unit, width, height, depth, unit weight, material, unit price, currency, brand, standards, manufacturing country, image, drawing, and additional material description files (Kong et al. 2004). The buyers could provide their requirements such as brand, model, quality and price to search and browse different types of products and make transactions with low transaction costs at any time and any place that is convenient to them ( $\mathrm{Li}$ et al. 2003). E-procurement construction trading markets are not restricted by the time and space limitations of store spaces and can carry a much larger variety of products with different styles and sizes. E-commerce procurement platform provides a central working platform for all construction material procurement participants and other related suppliers, which is shown in Fig. 1.

Grilo and Jardim-Goncalves (2011) presented an eprocurement process as depicted in Fig. 2. Webpage that describes companies' services and products is the simplest and most common usage of e-procurement by AEC players (Grilo, Jardim-Goncalves 2011). Two examples of tendering, biding and procurement related websites are shown in Table 1.
E-procurement in AEC has certain limitations and it is rarely explored to its fullest in construction despite the availability of this technology. Grilo and JardimGoncalves (2011) state that the AEC sectors still have been well lagging behind other sectors like retailing and automotive sectors in the adoption of e-procurement. Serious interoperability problems hinder further take up of electronic business tools (Mell, Grance 2010). A typical reason lies in the lack of integration of the companies' internal ERP systems with the marketplaces. Most companies type the transactional information into a web browser and receive data in a file that could be printed before data is reintroduced manually into their ERP systems (Mell, Grance 2010).

E-procurement process first requires construction contractors to make long time of material quantity takeoff, prepare site schedule requirement, make cost estimating, search supplier price and other relative information, and inquire desired information from suppliers. When any change or alteration is made to any one drawing or document, architects or engineers have to make related changes or alterations in each related drawing, and contractors, estimators and site engineers have to modify relevant material specifications, quantity takeoff and estimate data, and arrange new site schedule of material

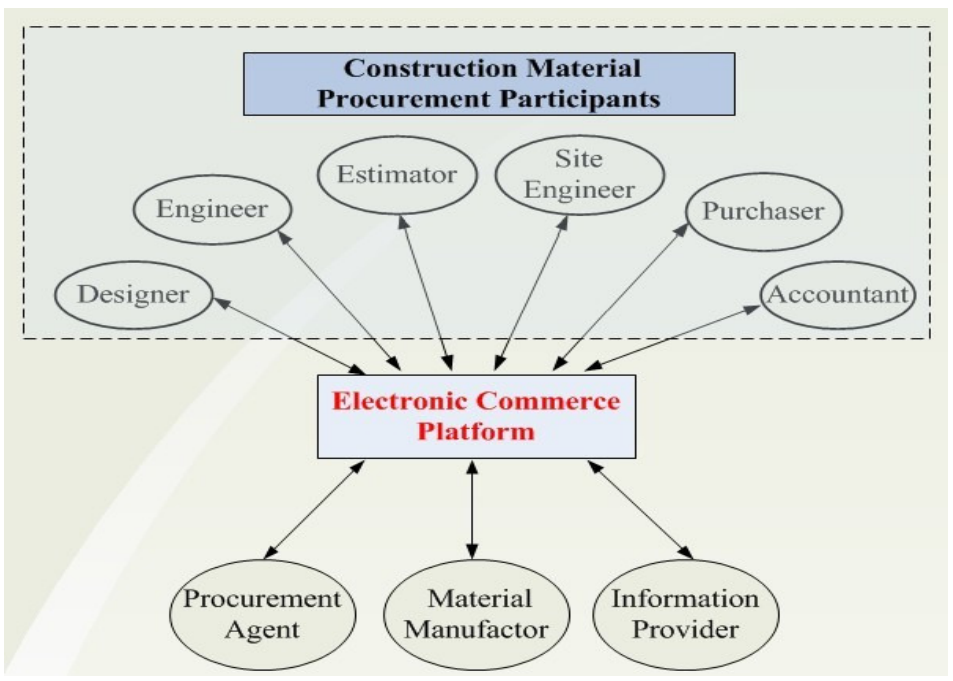

Fig. 1. E-commerce platform for construction material procurement participants

Table 1. Construction tendering, biding and procurement related websites

\begin{tabular}{|c|c|c|}
\hline General classification & Function/Description & Web URL \\
\hline $\begin{array}{l}\text { Project management and } \\
\text { collaboration }\end{array}$ & $\begin{array}{l}\text { Share project documents, and on-line document man- } \\
\text { agement } \\
\text { Main services: upload or download documents, on-line } \\
\text { modification, storage document modification notes, pur- } \\
\text { sue document status }\end{array}$ & $\begin{array}{l}\text { www.activeproject.com } \\
\text { www.buzzsaw.com } \\
\text { www.buildonline.com } \\
\text { www.citadon.com } \\
\text { www.loadsping.com } \\
\end{array}$ \\
\hline $\begin{array}{l}\text { Project bidding and } \\
\text { procurement }\end{array}$ & $\begin{array}{l}\text { Provide construction products and services } \\
\text { Main services: electronic bidding, on-line product/service } \\
\text { classification, price data exchange, bidding management, } \\
\text { on-line purchasing }\end{array}$ & $\begin{array}{l}\text { http://www.isqft.com/new/ } \\
\text { www.ebidsystems.com } \\
\text { www.eu-supply.com } \\
\text { www.purchasepro.com } \\
\text { http://postclick.datafax.net/ } \\
\text { http://www.constructionwire.com/ } \\
\text { http://www.bidclerk.com/ } \\
\text { http://www.combinenet.com/ }\end{array}$ \\
\hline
\end{tabular}




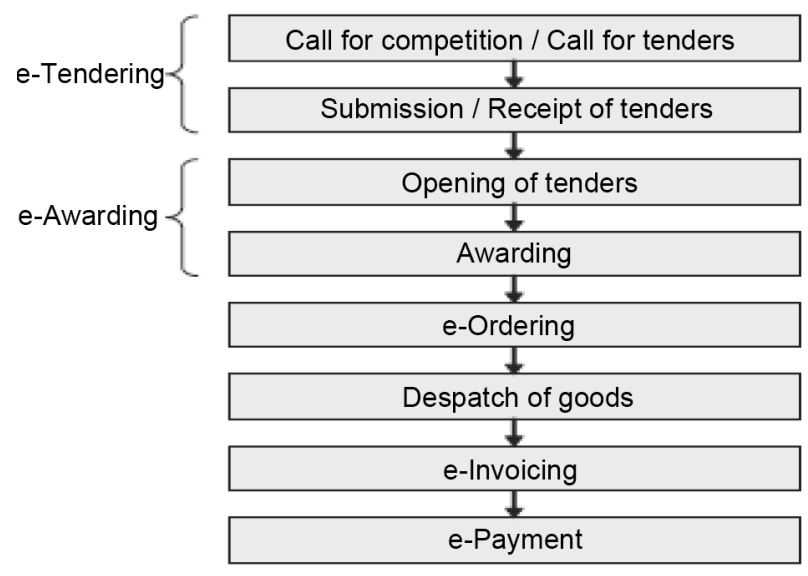

Fig. 2. Reference E-procurement process (Grilo, JardimGoncalves 2011)

requirements. This process requires close collaboration and cooperative work between designers, engineers, contractors, estimators, site staffs and purchasers, which is a time consuming and lengthy task and may lead to errors, mistakes, or modifications being missed out and overlooked and even minor unfavorable issues happening (Ruikar et al. 2003). E-procurement has limitations in dealing with these above practical problems, and streaming the workflow during the quantity takeoff, estimating and bidding stages of the preconstruction interactions among suppliers, contractors and designers (Castro-Lacouture et al. 2007).

Literature review reveals that e-procurement might not be suitable for detailed specification of goods or services where tight relationships between buyers and suppliers are essential (Subramaniam, Shaw 2004). AEC sectors may include many procured goods and services and have a large number of complex levels of specifications parameters (Grilo, Jardim-Goncalves 2011). Entering the specifications into web-based forms of several ecommerce sites to find the best product is a time consuming task for a contractor. A contractor has to acquire and maintain a list of several web addresses, interpret and understand the semantics and navigation methods used in different sites, be aware of new sites coming into the markets, and implement an evaluation of all the information acquired from different websites (Kong et al. 2004). The aggregation of information through e-market places may overcome some of these difficulties but does not eliminate all of them (Pahwa et al. 2006). Different emarketplaces have their own material searching and displaying patterns and adopt different attributes for storing construction material data and information (Kong et al. 2004). When two suppliers that sell the same or similar products store product descriptions differently using different attributes, it becomes difficult for a contractor to identify the similarities and differences. Construction material information systems are normally isolated and have few interactions between each other (Kong et al. 2004). Although request for quotations/proposals may reduce part of the problems if the information product is highly structured, it is still difficult for a contractor to discover all the information using one system and even more difficult to do comparison of the products supplied by different suppliers based on criteria such as product specifications, cost, availability, and delivery time. Grilo and Jardim-Goncalves (2011) point out that the AEC sectors are characterized by the procurement of complex levels of unstructured goods and services, and e-procurement solutions are required to develop solutions to successfully cope with the challenges of procuring unstructured goods and services.

\subsection{Building Information Modeling in material procurement}

Building Information Modeling (BIM) has become an active research area to solve the problems that are related to building information integration and interoperability (Isikdag, Underwood 2010). Several definitions of BIM can be discovered in the technical literature. Penttilä (2006) defines BIM as a set of interacting policies, processes and technologies generating a "methodology to manage the essential building design and project data in digital format throughout the building's life cycle". The National Building Information Model Standard Project Committee (NBIMS) divides the BIM categories in three axes which are Product, Collaborative Process and Facility. The Product is an intelligent digital representation of the building. The Collaborative Process covers business drivers, automated process capabilities and open information standards used for information sustainability and fidelity. The Facility concerns the well-understood information exchanges, workflows, and procedures in which teams use as repeatable, verifiable and sustainable information-based environment throughout the building's lifecycle (NBIMS 2007).

The core attributes of BIM that distinguish it from the advanced design technologies is not three dimensional geometric modeling, but structured information that could be organized, defined and exchanged (Smith, Tardif 2009). The perspective to understand BIM should be focused on the business process used to create modeling instead of model itself. BIM structured information provides the potential for more effective and efficient building information transfer at every critical juncture of building stewardship transfer (Smith, Tardif 2009). BIM opens the door to ample and remarkable business opportunities for the architects with insights to perceive and exploit them (Smith, Tardif 2009), and to maintain a more accurate and complex documentary record of building information throughout the building design and construction process. BIM allows the architecture profession to assert a leadership throughout lifecycle of buildings. BIM includes three interrelated fields which are policy, process and technology fields, which is shown in Fig. 3.

Fragmentation is a key feature of the construction industry. The traditional nature of the industry involves bringing together multi-disciplinary practitioners in one project and requires a tremendous amount of collaboration and coordination (Isikdag, Underwood 2010). BIM changes the way companies in the AEC sector are working, and provides the new processes for collaboration (Grilo, JardimGoncalves 2010). BIM is promising to be the facilitators of integration, interoperability and collaboration for the future construction industry (Isikdag, Underwood 2010). 


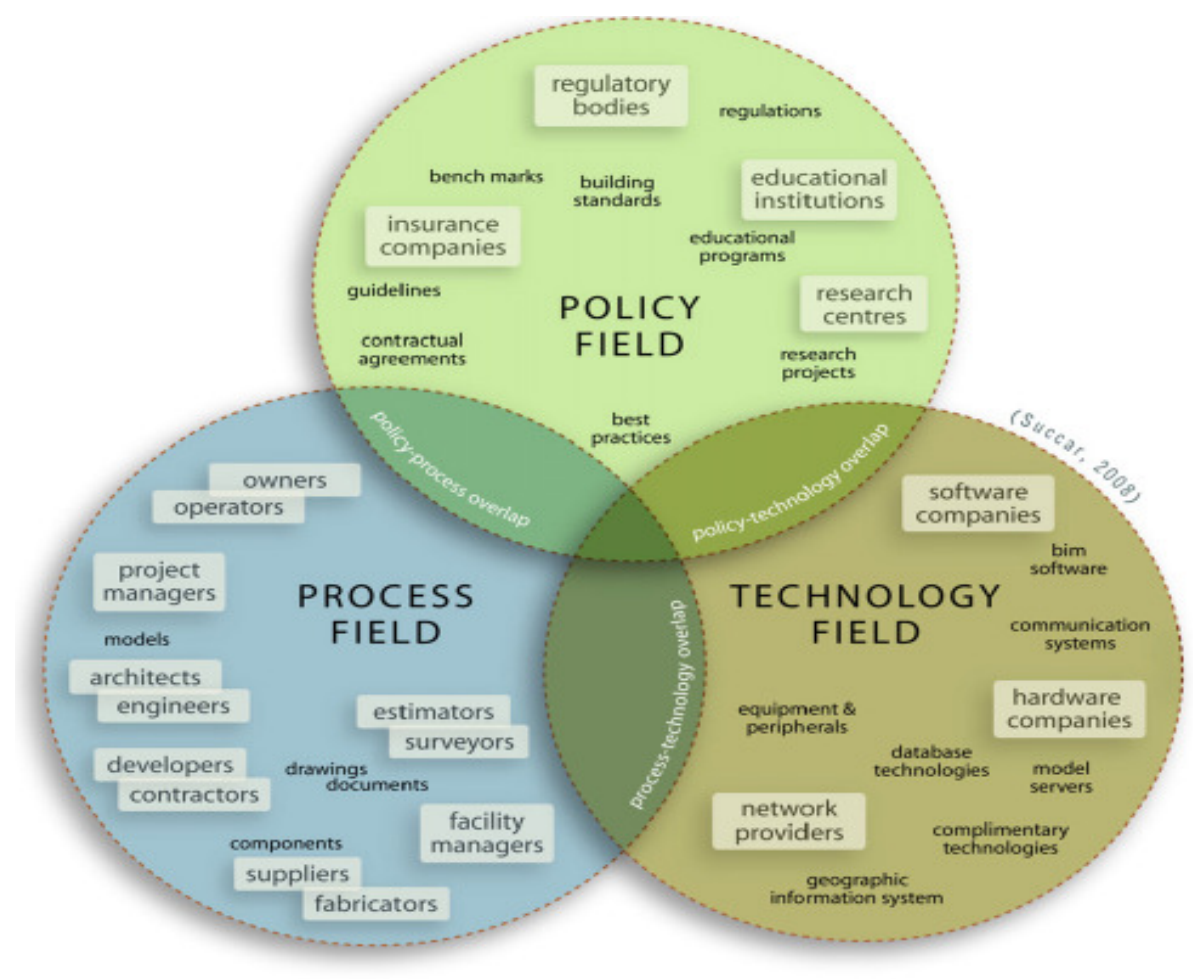

Fig. 3. Three interrelated fields of BIM (Succar 2009)

BIM refers to managing information from being generated throughout the whole processes comprehensively and not just simple information model. BIM fosters the continuity of information and workflow, and provides a powerful incentive for early and intensive collaboration (Smith, Tardif 2009). Specifically, BIM can support collaborative working environments because it enables the owner to develop an accurate understanding of the nature and needs of the purpose for the project, the design, development, and analysis of the project, the management of the construction of the project, and the management of the operations of the project during its operation and decommissioning. BIM allows the applications to exchange and share data using various procedures including STEP, IFC, XML which are being developed for the interoperability of data in International Organization for Standardization (ISO) and International Alliance for Interoperability (IAI) to solve the problems of data compatibility and interpreted differently by various software (Ham et al. 2008).

Interactions are important in virtual building simulations, and various types of links may be established during the development of BIM models. Interactions refer to the interconnection of different sources of information. This information may be part of the 3D model, or could be contained in another format file that is separate from the model file itself, such as in a schedule, a spreadsheet, a database, or a text document. Whenever the interaction involves the components of the 3D model, a common link in BIM and the interoperability of various models that may have been created by different software tools is required to exist (Europe Innova 2008).

Since the early 1990's, comprehensive efforts are being made to develop standards to define interoperabili- ty between models. This means that it is necessary for all of them to be translated into a file format for a model to be able to be compatible with models created by other software tools, so that all of the object's information can be transferred correctly. In most cases it is a challenge for such a translation to retain all the information that the model contains in its original native file format. Specific software tools can have a built-in capacity to ensure the ability to read and use the file format of other modelers. A number of larger modeling software companies are now developing suites of modeling and constructionrelated software tools that are interoperable. However, most of the BIM modeling applications and their complementary software tools only address interoperability among themselves and not in relation to other vendors' application systems (Grilo, Jardim-Goncalves 2010).

Literature review reveals that few efforts have been directed to the application of BIM for e-procurement (Grilo, Jardim-Goncalves 2011). Grilo and JardimGoncalves (2011) depicted how BIM combined with the Model Driven Architecture, Service Oriented Architecture, and Cloud Computing may challenge e-procurement in the AEC sectors, and presented the application of a SOA4BIM framework in the context of electronic procurement and described an industrial research case study for validation of the proposed approach in the conception and design phases of building/construction projects.

Grilo and Jardim-Goncalves (2010) hold the view that the interoperability factors may become more acute if one goal of e-platforms is to enhance the collaborative functions of BIM with traditional e-procurement and e-sourcing functions, where building product objects besides parametric $3 \mathrm{D}$ model information must be coupled with transactional information such as in RFP, Orders 
and Invoices. As each building/engineering project tends to be unique, it is critical for the e-procurement success that the BIM approach adopts the usage of universal interoperability standards for the various dimensions not only on the e-tendering, e-ordering, e-invoicing or e-catalogues, but also on product and process models (Grilo, Jardim-Goncalves 2011).

A purpose-built BIM solution features computable building information that enables a model to be understood by a computer as a building by three dimensional, real-time, dynamic building modeling software in building design and construction (Autodesk 2007). One of the potential benefits of exchanging BIM data between an architect and a contractor is a reduction in the time needed for quantity takeoffs.

Conceptually, construction design, shop drawing preparation, quantity takeoff and material procurement are a series of related processes. Historically, accurate quantity takeoffs have been the responsibility of constructors that are solely responsible for the material quantities accuracy (Smith, Tardif 2009). In traditional cost estimating solutions, material quantity takeoff is done by human efforts from the CAD drawings, which introduces the more potential for human errors and propagates any inaccuracies and involves much waste and inefficiency. When the designers or engineers change the information in any view, traditional material method requires lots of working time and human labor to make modification on all views, schedules, material take off, and so on. With BIM, building material quantity takeoff information, specifications, referenced standards, warranties and operational requirements can be extracted from a BIM model created by design professionals. An architect might understandably have concern that a contractor will rely on the model and hold the architect accountable for material quantities. Architects could use the information within their design models to easily double check estimating quantities to facilitate concurrent estimating during the design process. With BIM, when the design or shop drawing changes the information in any view, all views, schedules and material takeoffs could update automatically, and information across all representations of the project is reliable, coordinated, and internally consistent. BIM offers significant advantages over traditional drawing-based systems by minimizing manual takeoffs, facilitating improved communication, coordination and collaboration, reducing time and cost, and resulting in less misunderstanding between owners, designers, engineers, contractors, fabricators, facility operators across the whole construction industry in material quantity takeoff and cost estimating process, therefore it will provide more accurate material cost standards to evaluate the quotes from potential suppliers in the tendering, bidding and awarding process. Reducing the quantification effort means that contractors can apply their time and knowledge to higher value estimating activities including construction assemblies, generating pricing, factoring risks and so forth more effectively (Autodesk 2007).

Presently, Autodesk, Bentley, Graphisoft and Nemetschek are among the most popular BIM construction software providers to the construction industry. BIM authoring tools include Autodesk Revit, Bentley Architecture, Graphisoft ArchiCAD and Nemetschek Vectorworks (Smith, Tardif 2009). Popular commercial BIM based construction material quantity takeoff and cost estimating software include Autodesk Quantity Takeoff (QTO), Innovaya Visual Quantity Takeoff, Tocoman Quantity Takeoff and Vico Takeoff Manager.

\subsection{Material supplier performance evaluation}

Supplier performance evaluation has been important in operational decisions, involving decisions of selecting which vendors to employ, as well as decisions of quantities to order from each vendor.

The reasons to incorporate supplier performance evaluation function in BIM integrated with e-commerce software solutions include the following 3 aspects:

- First, supplier performance evaluation is the premise and important procedure in material supplier selection, supplier awarding and electronic material procurement process. Therefore, supplier performance evaluation should be one function module incorporated into BIM integrated with e-commerce material quantity takeoff, cost estimating and procurement software solutions, and it is one important part of BIM integrated with e-commerce material procurement framework;

- Second, BIM integrated with e-commerce material system solutions provide one innovative approach and improved way for material procurement process. Supplier performance evaluation module based on BIM integrated with e-commerce material system solutions will be more accurate and precise, and it will provide more objective and better reference for future supplier selection decision making in material procurement process;

- Third, BIM integrated with e-commerce material procurement process and supplier performance evaluation are interrelated processes, so BIM integrated with e-commerce material procurement system should incorporate a material supplier performance evaluation module.

Substantial research literature has been developed over the last two decades on the subject of using decision tools for supplier selection and evaluation in the supply chain management. Willis et al. (1993) classified supplier performance evaluation models into categorical, weighted points, and cost ratio approaches. Vonderembse and Tracey (1999) presented supplier evaluation criteria from five aspects including plant stoppages decreased, percent on-time delivery increased, timely material deliver, intransit damage reduced and high quality incoming parts. Kannan and Tan (2002) present assessment criteria to study the importance of these criteria of American manufacturing company for items to be used in products. These criteria include quality level, service level, correct quantity, on-time delivery, price/cost of product, use of electronic data interchange, willing to share sensitive 
information, presence of certification or other documents, the flexibility to respond to unexpected demand changes, communication skill/systems, quick response time in case of emergency, problem or special request, willingness to change products and services to meet the changing needs, willingness to participate in new products' development and value analysis. Wu and Blackhurst (2009) proposed an augmented DEA approach to evaluate supplier performance from quality, price, deliveries and cost reduction performance aspects. Chen (2011) proposed structured methodology for supplier selection and evaluation in supply chain with criteria and indicators from competition and organization factors and it is shown in Fig. 4.

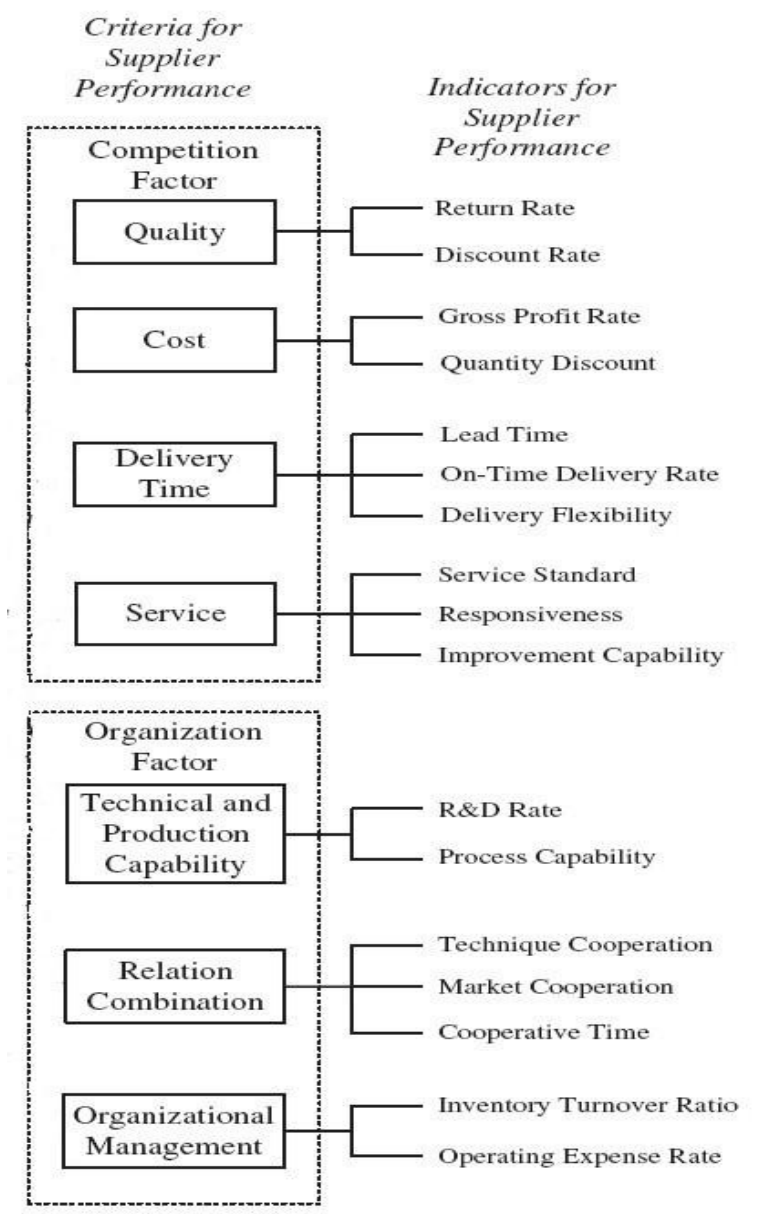

Fig. 4. Supplier performance criteria and indicators (Chen 2011)

\section{Proposed BIM integrated with e-commerce tools for material procurement}

\subsection{Proposed BIM integrated with e-commerce framework}

Based on the research about BIM and e-commerce in construction material quantity takeoff, cost estimating and material procurement solutions, and the generic SOA4BIM framework presented by Grilo and Jardim-Goncalves (2011), a primary and basic framework of BIM integrated with e-commerce solution in material quantity takeoff, cost estimating, material procurement and supplier performance evaluation application is proposed in Fig. 5.
In this framework, BIM is the key process and supporting platform to standardize and integrate $3 \mathrm{D}$ vector data, material composition data, cost price data, bidding and tendering data, contractual data, project document data, material supplier data. This standardizing and integrating process is achieved through the operations of web service and internet agent tools and IFC/STEP standard transmission engine. Architect/engineers, contractors/ subcontractors, cost estimators, material purchasers, site engineers and accountants are the main process participants. Material quantity takeoff, cost estimating, bidding and tending, e-procurement, and supplier performance evaluation and management process are based on BIM platform. Material suppliers, procurement agents and information providers take part in this process through web service/internet engine.

\subsection{Proposed material quantity takeoff and cost estimating platform and cost data source}

After the comparison of different BIM software, Autodesk Revit platform is chosen as BIM development platform for material quantity takeoff. Autodesk Revit has released comprehensive Application Programming Interface (API) and Software Development Kit (SDK), which are convenient for developers to make secondary development on Revit platform to generate quantity takeoff report. BIM design document could be generated, imported, modified or saved in Autodesk Revit platform.

RS Means Unit Price material cost data is adopted as cost price data source. Quantity takeoff result from BIM design documents in Revit platform will be linked with RS Means Unit Price material cost data to generate cost estimating report. This solution has advantage over traditional commercial quantity takeoff software such as QTO, Innovaya Visual Quantity Takeoff, Tocoman Quantity Takeoff and Vico Takeoff because none of these commercial software links quantity takeoff data from BIM design documents with RS Means Unit Price material cost data. Cost estimating information generated in this software module will potentially have better accuracy over traditional cost estimating methods and will provide a better cost standard for the future supplier quotes evaluation and supplier selection.

\subsection{Proposed supplier performance evaluation model}

Supplier performance evaluation and Information Management is one important function of BIM integrated with e-commerce framework in material procurement. Based on comprehensive literature review and studying the feasibility and practicability of supplier performance evaluation, the authors present ten main evaluation criteria which are Cost (C), Quality (Q), Delivery (D), Service (S), Assurance of Supply(AS), Overall Ability (OA), Payment Terms (PT), Information Sharing (IS), Reputation (R) and Buyer-Supplier Relationship (BSR). Each evaluation criterion also comprises several performance indicators. All evaluation criteria and performance indicators are shown in Table 2. 
Based on the literature review, system operability and applicability of the performance evaluation methods, a simple weight coefficient method is designed, presented and adopted in this framework. Each evaluation criterion is provided with a weight coefficient from any number between 1 and 5 . Weight coefficient 1 represents this criterion is totally unimportant. Weight coefficient 2 represents this criterion is fairly unimportant. Weight coefficient 3 represents this criterion is neither unimportant nor important. Weight coefficient 4 represents this criterion is fairly important. Weight coefficient 5 represents that this criterion is very important.

Each performance indicator is provided with a weight coefficient and optional choice from any number between 1 and 5 . Weight coefficient 1 represents this indicator is totally unimportant. Weight coefficient 2 represents this indicator is fairly unimportant. Weight coefficient 3 represents this indicator is neither unimportant nor important. Weight coefficient 4 represents this indicator is fairly important. Weight coefficient 5 represents this indicator is very important. User choice 1 represents supplier performance in this indicator is totally unsatisfactory. User choice 2 represents supplier performance in this indicator is fairly unsatisfactory. User choice 3 represents supplier performance in this indicator is neither unsatisfactory nor satisfactory. User choice 4 represents supplier performance in this indicator is fairly satisfactory. User choice 5 represents supplier performance in this indicator is very satisfactory.
In this framework, Single Performance Indicator Value (SPIV) is calculated by multiplying User Choice and Weight Coefficient of this performance indicator; Single Evaluation Criterion Value (SECV) is calculated by multiplying the sum of SPIV belonging to this evaluation criterion and Weight Coefficient of this evaluation criterion. Total Evaluation Criterion Value (TECV) is the sum of SECV. The specific functions to calculate SPIV, SECV and TECV are displayed from Eqs 1 to 3, respectively:

Single Performance Indicator Value $(S P I V)=$ $\sum$ Weight Coefficient *

User Choice of this Performance Indicator;

Single Evaluation Criterion Value $($ SECV $)=$ ( $\sum$ Single Performance Indicator Value (SPIV)) * Weight Coefficient of this Evaluation Criterion;

\section{Total Evaluation Criterion Value $(T E C V)=$ $\sum$ Single Evaluation Criterion Value (SECV).}

Performance of all material suppliers could be evaluated, compared and ranked according to the standard of SPIV, SECV or TECV in one project, or according to the standard of average SPIV, SECV or TECV of each supplier in multiple projects. All the data and results will provide reference for the future decision making in potential supplier selection in e-awarding process.

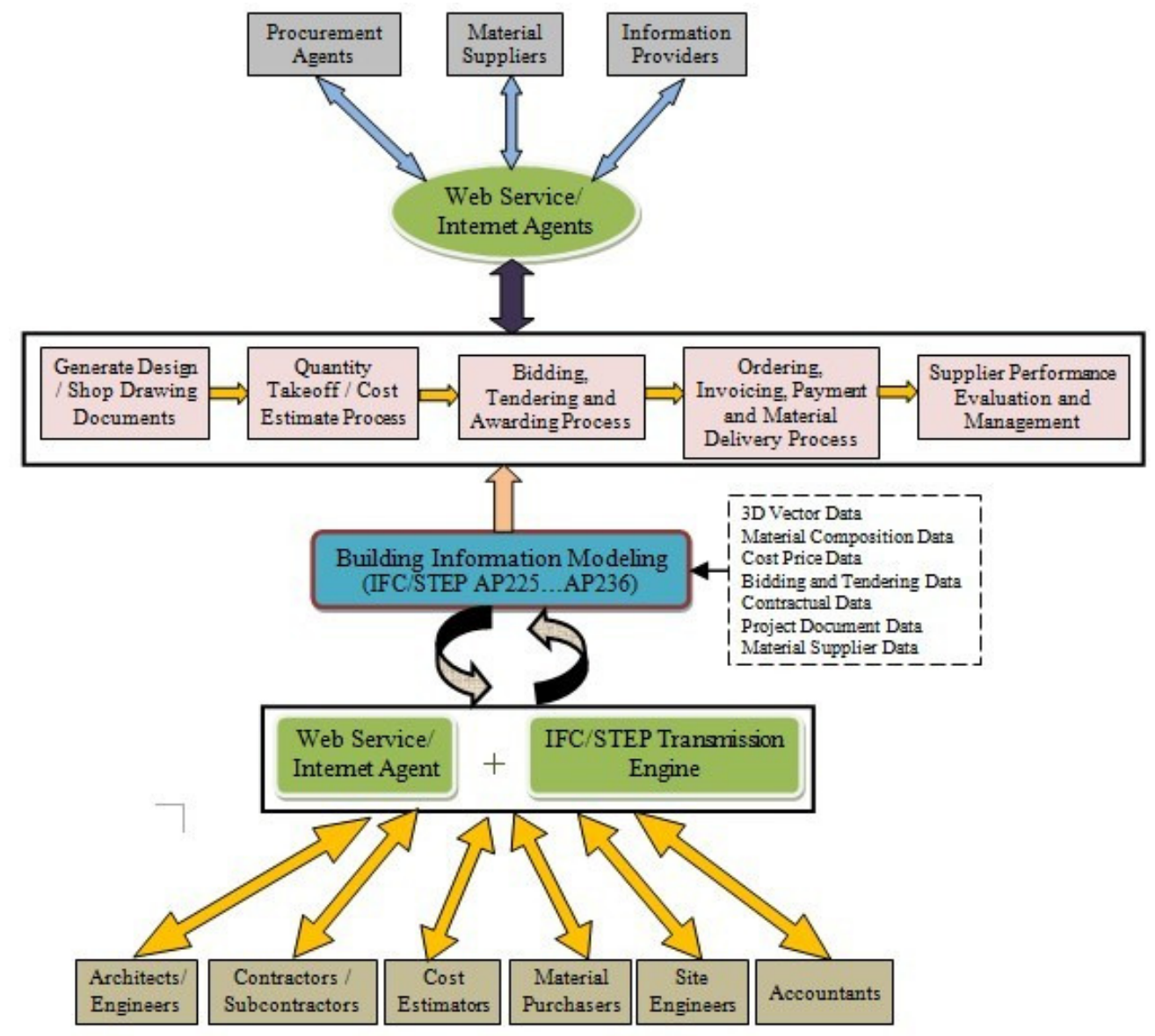

Fig. 5. Framework of BIM integrated with e-commerce solutions 
Table 2. Supplier performance evaluation criteria and performance indicators

\begin{tabular}{|c|c|c|c|}
\hline Evaluation Criteria & Performance Indicator & Weight Coefficient (1 to 5) & User Choice (1 to 5$)$ \\
\hline \multirow{3}{*}{ Cost ( C) } & Total Cost (TC) (Lam et al. 2010) & 1 ㄷ 2 Г Г 4 Г 5 Г & $1 \sqsubseteq 2 \sqsubseteq 3 \sqsubseteq 4 \sqsubseteq 5$ Г \\
\hline & Price Stability (PS) (Lam et al. 2010) & 1 ㄷ 2 Г 4 Г 5 Г & 1 ㄷ3 3 Г 4 Г 5 \\
\hline & Discount Rate (DR) (Chen 2011) & $1 \sqsubseteq 2 \sqsubseteq 3 \sqsubseteq 4 \sqsubseteq 5$ Г & $1 \sqsubseteq 2 \sqsubseteq 3 \sqsubseteq 4 \sqsubseteq 5$ Г \\
\hline \multirow{3}{*}{ Quality (Q) } & Return Rate (RR) (Chen 2011) & $1 \sqsubseteq 2 \sqsubseteq 3 \sqsubseteq 4 \sqsubseteq 5 \sqsubseteq$ & $1 \sqsubseteq 2 \sqsubseteq 3 \sqsubseteq 4 \sqsubseteq 5 \sqsubseteq$ \\
\hline & $\begin{array}{l}\text { Failure Prevention (FP) } \\
(\text { Lam et al. 2010) }\end{array}$ & $1 \sqsubseteq 2 \sqsubseteq 3 \sqsubseteq 4 \sqsubseteq 5 \sqsubseteq$ & $1 \sqsubseteq 2 \sqsubseteq 3 \sqsubseteq 4 \Gamma 5$ Г \\
\hline & $\begin{array}{l}\text { Appearance and Function (AF) } \\
\text { (Lam et al. 2010) }\end{array}$ & $1 \sqsubseteq 2 \sqsubseteq 3 \sqsubseteq 4 \sqsubseteq 5 \sqsubseteq$ & $1 \sqsubseteq 2 \sqsubseteq 3 \sqsubseteq 4 \sqsubseteq 5$ Г \\
\hline \multirow{3}{*}{ Delivery (D) } & Lead Time (LT) (Chen 2011) & $1 \sqsubseteq 2 \sqsubseteq 3 \sqsubseteq 4 \sqsubseteq 5 \sqsubseteq$ & $1 \sqsubseteq 2 \sqsubseteq 3 \sqsubseteq 4 \sqsubseteq 5 \sqsubseteq$ \\
\hline & $\begin{array}{l}\text { On-Time Delivery (OTD) } \\
\text { (Chen 2011) }\end{array}$ & $1 \sqsubseteq 2 \sqsubseteq 3 \sqsubseteq 4 \Gamma 5 \sqsubseteq$ & $1 \sqsubseteq 2 \sqsubseteq 3 \sqsubseteq 4 \Gamma 5 \sqsubset$ \\
\hline & $\begin{array}{l}\text { Delivery Flexibility (DF) } \\
\text { (Chen 2011) }\end{array}$ & $1 \sqsubseteq 2 \sqsubseteq 3 \sqsubseteq 4 \sqsubseteq 5 \sqsubseteq$ & 1 드 3 Г 4 Г 5 Г \\
\hline \multirow{4}{*}{ Service (S) } & Service Standard (SS) (Chen 2011) & $1 \sqsubseteq 2 \sqsubseteq 3 \sqsubseteq 4 \sqsubseteq 5 \sqsubseteq$ & $1 \sqsubseteq 2 \sqsubseteq 3 \sqsubseteq 4 \sqsubseteq 5 \sqsubseteq$ \\
\hline & $\begin{array}{l}\text { Technical Assistance \& Support } \\
\text { (TAS) (Lam et al. 2010) }\end{array}$ & $1 \sqsubseteq 2 \sqsubseteq 3 \sqsubseteq 4 \sqsubseteq 5 \sqsubseteq$ & $1 \sqsubseteq 2 \sqsubseteq 3 \sqsubseteq 4 \sqsubseteq 5 \sqsubseteq$ \\
\hline & $\begin{array}{l}\text { Cooperation \& Communication } \\
(\mathrm{C} \& C)(\text { Lam et al. 2010) }\end{array}$ & $1 \sqsubseteq 2 \sqsubseteq 3 \sqsubseteq 4 \sqsubseteq 5 \sqsubseteq$ & $1 \sqsubseteq 2 \sqsubseteq 3 \sqsubseteq 4 \sqsubseteq 5 \sqsubseteq$ \\
\hline & Responsive Time (RT) (Chen 2011) & $1 \sqsubseteq 2 \sqsubseteq 3 \sqsubseteq 4 \sqsubseteq 5 \sqsubseteq$ & $1 \sqsubseteq 2 \sqsubseteq 3 \sqsubseteq 4 \sqsubset 5 \sqsubset$ \\
\hline \multirow{3}{*}{$\begin{array}{l}\text { Assurance of } \\
\text { Supply (AS) }\end{array}$} & Capability (C) (Lam et al. 2010) & $1 \sqsubseteq 2 \sqsubseteq 3 \sqsubseteq 4 \sqsubseteq 5 \sqsubseteq$ & $1 \sqsubseteq 2 \sqsubseteq 3 \sqsubseteq 4 \sqsubseteq 5 \sqsubseteq$ \\
\hline & Reliability (R) (Lam et al. 2010) & $1 \sqsubseteq 2 \sqsubseteq 3 \sqsubseteq 4 \sqsubseteq 5 \sqsubseteq$ & $1 \sqsubseteq 2 \sqsubseteq 3 \sqsubseteq 4 \sqsubseteq 5 \sqsubseteq$ \\
\hline & Flexibility (F) (Lam et al. 2010) & $1 \sqsubseteq 2 \sqsubseteq 3 \sqsubseteq 4 \sqsubseteq 5 \sqsubseteq$ & $1 \sqsubseteq 2 \sqsubseteq 3 \sqsubseteq 4 \sqsubseteq 5 \sqsubseteq$ \\
\hline \multirow{4}{*}{$\begin{array}{l}\text { Overall Ability } \\
\text { (OA) }\end{array}$} & Technical Ability (TA) & $1 \sqsubset 2 \sqsubset 3 \sqsubseteq 4 \sqsubset 5 \sqsubset$ & $1 \sqsubseteq 2 \sqsubseteq 3 \sqsubseteq 4 \sqsubseteq 5 \sqsubseteq$ \\
\hline & Conform to BIM Standard & $1 \sqsubseteq 2 \sqsubseteq 3 \sqsubseteq 4 \sqsubseteq 5 \sqsubseteq$ & $1 \sqsubseteq 2 \sqsubseteq 3 \sqsubseteq 4 \sqsubseteq 5$ Г \\
\hline & Management Ability (MA) & $1 \sqsubseteq 2 \sqsubseteq 3 \sqsubseteq 4 \sqsubseteq 5 \sqsubseteq$ & $1 \sqsubseteq 2 \sqsubseteq 3 \sqsubseteq 4 \sqsubseteq 5$ Г \\
\hline & Production Ability (PA) & $1 \sqsubseteq 2 \sqsubseteq 3 \sqsubseteq 4 \sqsubseteq 5 \sqsubseteq$ & $1 \sqsubseteq 2 \sqsubseteq 3 \sqsubseteq 4 \sqsubseteq 5 \sqsubseteq$ \\
\hline \multirow{2}{*}{$\begin{array}{l}\text { Payment Terms } \\
\text { (PT) }\end{array}$} & $\begin{array}{l}\text { Standard Payment (SP) } \\
(\text { Lam et al. 2010) }\end{array}$ & 1 드 3 Г 4 Г & $1 \sqsubseteq 2 \sqsubseteq 3 \sqsubseteq 4$ Г \\
\hline & $\begin{array}{l}\text { Payment Flexibility (PF) } \\
(\text { Lam et al. 2010) }\end{array}$ & $1 \sqsubseteq 2 \sqsubseteq 3 \sqsubseteq 4 \sqsubseteq 5 \sqsubseteq$ & 1 드 3 Г 4 Г 5 Г \\
\hline \multirow{2}{*}{$\begin{array}{l}\text { Information Sharing } \\
\text { (IS) }\end{array}$} & $\begin{array}{l}\text { Use of Electronic Data Interchange } \\
\text { (UEDA) (Kannan, Tan 2002) }\end{array}$ & $1 \sqsubseteq 2 \sqsubseteq 3 \sqsubseteq 4 \sqsubseteq 5 \Gamma$ & $1 \sqsubseteq 2 \sqsubseteq 3 \sqsubseteq 4 \sqsubseteq 5 \sqsubset$ \\
\hline & $\begin{array}{l}\text { Willing to Share Sensitive Informa- } \\
\text { tion (WSSI) (Kannan, Tan 2002) }\end{array}$ & $1 \sqsubseteq 2 \sqsubseteq 3 \sqsubseteq 4 \sqsubseteq 5 \sqsubseteq$ & $1 \sqsubseteq 2 \sqsubseteq 3 \sqsubseteq 4 \sqsubseteq 5 \sqsubseteq$ \\
\hline \multirow{4}{*}{ Reputation (R) } & $\begin{array}{l}\text { Commitment to Quality (CQ) } \\
\text { (Kannan, Tan 2002) }\end{array}$ & 1 드 3 Г 4 Г & 1 두 3 Г 4 Г 5 \\
\hline & $\begin{array}{l}\text { Ability to Meet Due Date (AMDD) } \\
\text { (Kannan, Tan 2002) }\end{array}$ & $1 \sqsubseteq 2 \sqsubseteq 3 \sqsubseteq 4 \sqsubseteq 5 \sqsubseteq$ & $1 \sqsubseteq 2 \sqsubseteq 3 \sqsubseteq 4 \sqsubseteq 5$ Г \\
\hline & $\begin{array}{l}\text { Commitment to Continuous Impro- } \\
\text { vement (CCI) (Kannan, Tan 2002) }\end{array}$ & $1 \sqsubseteq 2 \sqsubseteq 3 \sqsubseteq 4 \sqsubseteq 5 \sqsubseteq$ & $1 \sqsubseteq 2 \sqsubseteq 3 \sqsubseteq 4 \sqsubseteq 5 \sqsubseteq$ \\
\hline & $\begin{array}{l}\text { Honesty Communication (HC) } \\
\text { (Kannan, Tan 2002) }\end{array}$ & $1 \sqsubseteq 2 \sqsubseteq 3 \sqsubseteq 4 \sqsubset 5 \sqsubseteq$ & $1 \sqsubseteq 2 \sqsubseteq 3 \sqsubseteq 4 \sqsubseteq 5 \sqsubseteq$ \\
\hline \multirow{3}{*}{$\begin{array}{l}\text { Buyer-Supplier } \\
\text { Relationship } \\
\text { (BSR) }\end{array}$} & $\begin{array}{l}\text { Geographical Compatibility } \\
\text { (Kannan, Tan 2002) }\end{array}$ & $1 \sqsubseteq 2 \sqsubseteq 3 \sqsubseteq 4 \sqsubseteq 5 \sqsubseteq$ & $1 \sqsubseteq 2 \sqsubseteq 3 \sqsubseteq 4 \sqsubseteq 5$ Г \\
\hline & Culture Match (Kannan, Tan 2002) & $1 \sqsubset 2 \sqsubseteq 3 \sqsubseteq 4 \sqsubseteq 5 \sqsubseteq$ & $1 \sqsubseteq 2 \sqsubseteq 3 \sqsubseteq 4 \sqsubseteq 5$ Г \\
\hline & $\begin{array}{l}\text { Past and Future Relationship } \\
\text { (Kannan, Tan 2002) }\end{array}$ & $1 \sqsubseteq 2 \sqsubseteq 3 \sqsubseteq 4 \sqsubseteq 5 \sqsubseteq$ & $1 \sqsubseteq 2 \sqsubseteq 3 \sqsubseteq 4 \sqsubseteq 5 \sqsubseteq$ \\
\hline
\end{tabular}




\section{BIM integrated with e-commerce software system prototype}

Construction software requires ease of installation and configuration, low cost, ease of connection and integration, ability to integrate external systems and information, and customizable access to information and applications (Cheng et al. 2010). Considering the technical complexity, system difficulty and time restraint, the authors designed and developed a fairly simple display version of the BIM integrated with e-commerce material procurement and supplier performance management system as the first step to implement the main functions of this framework.

\subsection{System design overview}

This system will implement the functions including design document management, material quantity takeoff, material cost estimating, tendering and bidding management, e-invoicing, e-payment and transaction history management, supplier performance valuation and information management, project document and information management, and user role and safety control. This sys- tem has been designed to include the following user roles: Designers/Engineers, Contractors, Estimators, Purchasers, Site Engineers, Accountants, Suppliers and Anonymous. For a specific system function, five different user access rights including No Purview, View, Add, Delete and Modify have been chosen to be designated to different user roles.

This system is designed to develop and operate on the combination of BIM platform and e-commerce platform:

- BIM Platform: This platform is designed with model import, add, view, modification or deletion, material quantity takeoff and cost estimating functions;

- E-Commerce Platform: This platform is adopted to implement bidding and tendering (BIM based) management, e-invoicing, e-payment and transaction history management, project document (BIM based) and information management, and supplier performance evaluation and information management functions.

General system architecture is displayed in Fig. 6.

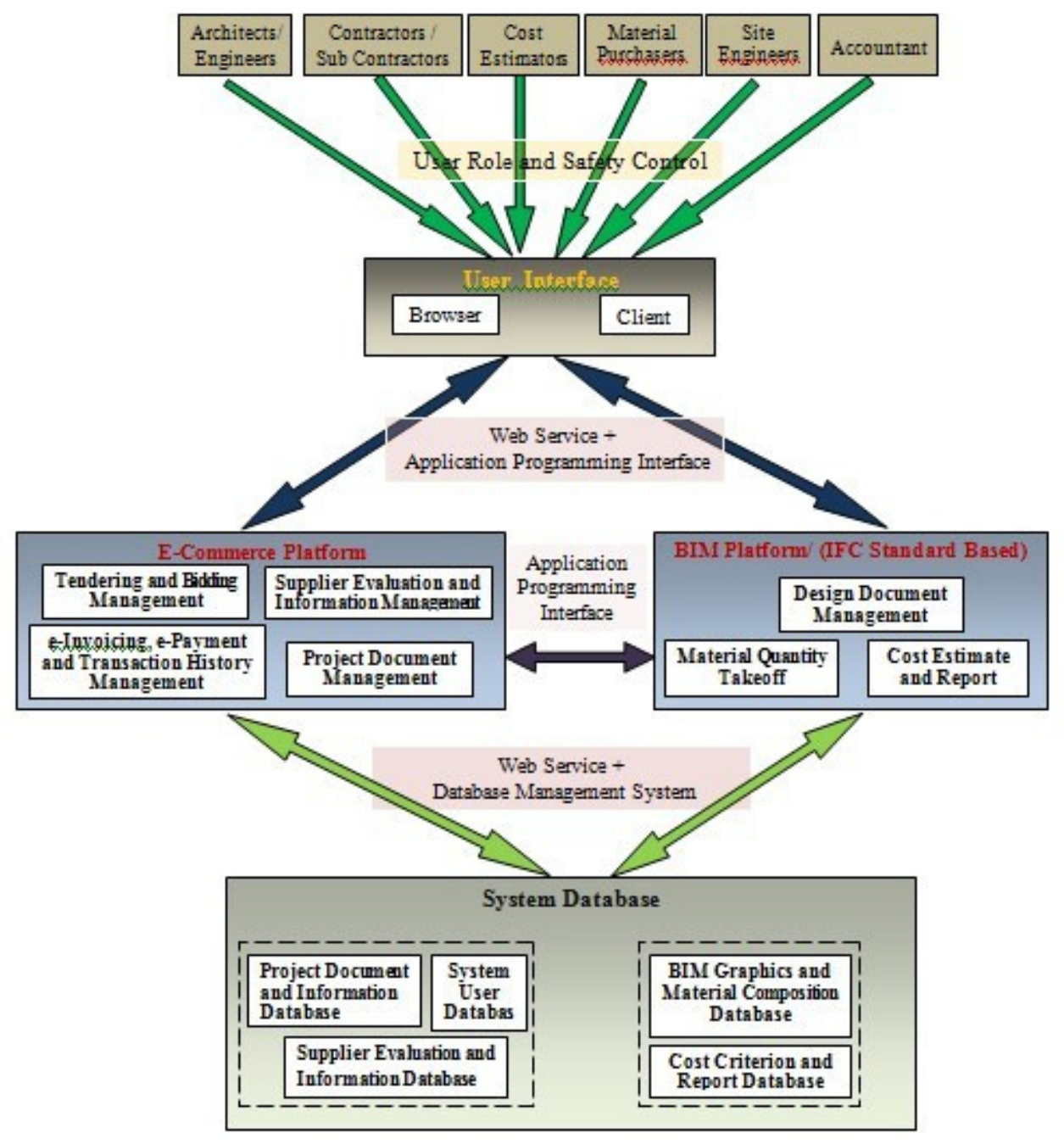

Fig. 6. BIM integrated with e-commerce software system architecture 
System users include the following different types including architects/engineers, contractors/ subcontractors, cost estimators, material purchasers, site engineers, accountants, suppliers and anonymous. Different users enter the system after the validation of user name and password from user role and safety control module. Different types of users have different access rights, and could only view or operate different modules within their access rights. The connection between user interface of e-commerce platform or BIM platform are web-service and Application Programming Interface (API), the connection between ecommerce and BIM platform is API, and the connections between e-commerce or BIM platform and database are web-service and database management system.

\subsection{System operation overview}

General Contractor is the system administrator responsible for all system operations and controls. After general contractors sign construction contract with the owner, general contractor will log in this system to begin to save and update project, owner, architect and various project document and activity information in this system. Architects and engineers are responsible for managements of all design documents, and will save and update all BIM based design documents in this system. Estimators are responsible for material quantity takeoff and cost estimating result, and could log into the system, choose the relevant project name, import design document name to quantity takeoff and cost estimating module, make BIMbased material quantity takeoff and cost estimating, generate quantity takeoff and cost estimating reports, save and update all relevant reports in this system before the call for material tenders process starts. Material cost estimating reports generated by estimators will provide a more accurate information reference for general contractors to release call for tenders file and evaluate material quotes from suppliers. Site engineers are responsible for the generation, saving, uploading, modification and management of site schedule based material requirement documents in this system.

After the material cost estimating reports and site schedule based material requirement documents are saved to system database, the general contractors will release "Call for Tenders" files according to the cost estimating reports and site schedule documents on this system. All system users including anonymous users could log in this system to view the ongoing and future "Call for Tenders" documents through this website. If one supplier has intention to bid for a material supplier, he or she will have to contact the general contractor to get an authorized formal user name and password in this system and use this user name and password to submit material quotes through this system during the required time. After all material quotes has been collected, the general contractors will evaluate all material quotes that have been submitted to this system and use the historical supplier performance evaluation information data which have been performed by contractors, estimators, site engineers, purchasers and accountants in the former projects as the references to make final awarding decisions and sign the material su- pplying contracts. The important supplier evaluation, awarding and contract signing information will be released on this website on time, and all system users could view such information from this website.

After the general contractor has signed material supplying contract with one supplier, the site engineers, purchasers and accountants will take their respective responsibilities in the latter material supplying process. They will be also responsible for saving, uploading, modifying and management of all relevant activities and documents in the software system.

\subsection{Operation of supplier performance evaluation module}

Supplier performance evaluation provides the valuable history reference data for contractors to select the best supplier in the future construction project, and it is one of key functions of this software system. Contractors, estimators, site engineers, purchasers and accountants are all authorized supplier performance evaluators. Construction contractors makes the final decision about how to evaluate and select potential material suppliers, so choosing and determining weight coefficient of all evaluation criteria and performance indicators is the responsibility and duty of construction contractors.

After procurement activities from one supplier have finished in one project, it is time for all authorized supplier performance evaluators to begin supplier performance evaluation process. Responsible construction contractors first $\log$ into this system to determine weight coefficient of each evaluation criterion and performance indicator for all suppliers in one project by choosing a number between 1 and 5 . Then for all authorized supplier performance evaluators, the choice value of each performance indicator should be selected according to evaluators' appraisal of each supplier's performance in a specific project. Each evaluator will choose a number between 1 and 5 in the value of user choice of each indicator according to the appraisal of this supplier's performance in this aspect of this project. After one evaluator finishes the evaluation of one supplier in one project, all evaluated data could be saved to system database. SPIV, SECV and TECV could be calculated automatically in each project.

All supplier performance evaluation data should be kept as the reference for future decision making process of material supplier selection. Each supplier performance evaluator could search project evaluation status, review his or her evaluation history, choose an available supplier and project to make evaluation or review past relevant detailed evaluation information. The system will also enable evaluators to select multiple suppliers' names and one project to view the comparison and rank information about evaluation scores of these different suppliers in one project, or select multiple projects' names and one supplier to view the comparison and rank information about evaluation scores of one supplier in different projects. 


\section{Conclusions and future research}

\subsection{Conclusions}

Based on the comprehensive literature review on ecommerce and BIM in construction quantity takeoff, cost estimating and material procurement, and supplier performance evaluation criteria and methods, and persistent efforts in software design and development, the authors presented a framework and displayed one development solution to integrate BIM with e-commerce in quantity takeoff, cost estimating, material procurement and material supplier evaluation and information management. This research contributes to the innovation of the construction procurement processes through the use of BIM solutions and e-commerce tools in the following aspects:

- Provision of practical framework and made display version software system to integrate BIM in material quantity takeoff and cost estimating, e-commerce in material procurement activities including bidding and tendering, e-invoicing, e-payment and transaction history management and supplier performance evaluation and management, which has rarely been explored by other researcher before;

- Application of BIM in material quantity takeoff based on Autodesk Revit development platform, and linked BIM with RS Means Unit Price material cost criterion to generate material cost estimating report, which is different from commercial quantity takeoff software such as QTO, Innovaya Visual Quantity Takeoff, Tocoman Quantity Takeoff and Vico Takeoff. Cost information generated in this platform will have better accuracy over traditional cost estimating methods and will provide a better cost standard for the future supplier quote evaluation and supplier selection;

- Improved supplier performance evaluation criteria and performance indicators and an evaluation method using weight coefficient, which provides practical reference value for future supplier performance evaluation and selection in the eprocurement process.

\subsection{Future research}

Future research should concentrate on the following aspects:

- Research on the identification and analysis of cost, benefit and risk factors will provide useful data and reference for future software vendors to make decision about software design and development. Although many literatures have been explored cost, benefit and risk of e-commerce and BIM in construction, there is no ongoing research on the potential cost, benefit and risk factors of BIM integrated with e-commerce software system application in quantity takeoff, cost estimating, material procurement and supplier performance management process. Future research on potential cost, benefit and risk analysis of BIM integrated with e-commerce software system application in material quantity takeoff, cost estimating and material procurement process will be required;

- Computer Supported Cooperative Work (CSCW) is the technology which combines the understanding of the way people work in groups with the enabling technologies of computer networking, and associated hardware, software, services and techniques (Kamel, Davison 1998). BIM includes a database that comprises of computer three dimensional models and provides possibility for project members from various professional backgrounds to share the same data and work with the same model. BIM requires participants to develop closer relationships with key team members, fosters the open exchange of electronic information, and encourages closer collaboration than ever. BIM introduces new team dynamics, accelerated decision making, and complexities that demand a strong working relationship, so BIM is more suitable for cooperative work mode. Therefore, future work may concentrate on the framework of BIM, e-commerce and CSCW software integration solution in construction material procurement process;

- Material quantity takeoff, cost estimating, material procurement and supplier evaluation and information management are parts of issues of construction project lifecycle management, and the proposed framework and developed software system in this paper could be integrated with other project lifecycle management software systems in construction firms to streamline material procurement workflow and optimize system benefit. One potential future research is the integration and optimization of this proposed framework and developed system with present web-based project management or Enterprise Resource Planning (ERP) systems in construction firms.

\section{References}

Agapiou, A.; Flanagan, R.; Norman, G.; Notman, D. 1998. The changing role of builders merchants in the construction supply chain, Construction Management and Economics 16(3): 351-361.

http://dx.doi.org/10.1080/014461998372376

Anumba, C. J.; Ruikar, K. 2002. Electronic commerce in construction - trends and prospects, Automation in Construction 11(3): 265-275.

http://dx.doi.org/10.1016/S0926-5805(01)00087-5

Autodesk. 2007. Revit Building Information Modeling - BIM and Cost Estimating, BIM Concept to Completion, The Five Fallacies of BIM, Using BIM for Greener Designs, BIM and Project Planning, Transmitting to BIM. Available from Internet: $<$ http://www.autodesk.com>.

Castro-Lacouture, D.; Medaglia, A. L.; Skibniewski, M. 2007. Supply chain optimization tool for purchasing decisions in B2B construction marketplaces, Automation in Construction 16(5): 569-575.

http://dx.doi.org/10.1016/j.autcon.2006.08.005

Chen, Y.-J. 2011. Structured methodology for supplier selection and evaluation in a supply chain, Information Sciences 181(9): 1651-1670. http://dx.doi.org/10.1016/j.ins.2010.07.026 
Cheng, J. C. P.; Law, K. H.; Bjornsson, H.; Jones, A.; Sriram, R. 2010. A service oriented framework for construction supply chain integration, Automation in Construction 19(2): 245-260.

http://dx.doi.org/10.1016/j.autcon.2009.10.003

Europe Innova. 2008. The STAND-INN Handbook. Available from Internet: <http://standards.eu-innova.org/ StandInn/tooldetails.aspx?id $=172>$.

Grilo, A.; Jardim-Goncalves, R. 2010. Value proposition on interoperability of BIM and collaborative working environments, Automation in Construction 19(5): 522-530. http://dx.doi.org/10.1016/j.autcon.2009.11.003

Grilo, A.; Jardim-Goncalves, R. 2011. Challenging electronic procurement in the AEC sector: A BIM-based integrated perspective, Automation in Construction 20(2): 107-114. http://dx.doi.org/10.1016/j.autcon.2010.09.008

Ham, N. H.; Min, K. M.; Kim, J. H.; Lee, Y. S.; Kim, J. J. 2008. A study on application of BIM (Building Information Modeling) to predesign in construction project, in The Third 2008 International Conference on Convergence and Hybrid Information Technology, 11-13 November, 2008, Busan, Korea, 42-49.

Holness, G. V. R. 2008. Building Information Modeling: gaining momentum, ASHRAE Journal 50(6): 28-40.

Isikdag, U.; Underwood, J. 2010. Two design patterns for facilitating Building Information Model-based synchronous collaboration, Automation in Construction 19(5): 544553. http://dx.doi.org/10.1016/j.autcon.2009.11.006

Kamel, N. N.; Davison, R. M. 1998. Applying CSCW technology to overcome traditional barriers in group interactions, Information \& Management 34(4): 209-219. http://dx.doi.org/10.1016/S0378-7206(98)00056-1

Kannan, V. R.; Tan, K. C. 2002. Supplier selection and assessment: Their impact on business performance, Journal of Supply Chain Management 38(4): 11-21. http://dx.doi.org/10.1111/j.1745-493X.2002.tb00139.x

Kong, S. C. W.; Li, H.; Hung, T. P. L.; Shi, J. W. Z.; CastroLacouture, D.; Skibniewski, M. 2004. Enabling information sharing between e-Commerce systems for construction material procurement, Automation in Construction 13(2): 261-276.

http://dx.doi.org/10.1016/j.autcon.2003.08.011

Lam, K.-C.; Tao, R.; Lam, M. C.-K. 2010. A material supplier selection model for property developers using Fuzzy Principal Component Analysis, Automation in Construction 19(5): 608-618.

http://dx.doi.org/10.1016/j.autcon.2010.02.007

Li, H.; Cao J. N.; Castro-Lacouture, D.; Skibniewski, M. 2003. A framework for developing a unified B2B e-trading construction marketplace, Automation in Construction 12(2): 201-211.

http://dx.doi.org/10.1016/S0926-5805(02)00076-6

Mell, P.; Grance, T. 2010. Draft NIST Working Definition of Cloud Computing. Available from Internet: <http:// csrc.nist.gov/groups/SNS/cloud-computing/index.html>.

NBIMS. 2007. National Building Information Modeling Standard Part-1: Overview, Principles and Methodologies. US National Institute of Building Sciences. $161 \mathrm{p}$.

Pahwa, J. S.; Burnap, P.; Gray, W. A.; Miles, J. 2006. MDSSF a federated architecture for product procurement, Database and Expert Systems Applications, Lecture Notes in Computer Science 4080: 812-821.

http://dx.doi.org/10.1007/11827405_79

Penttilä, H. 2006. Describing the changes in architectural information technology to understand design complexity and free-form architectural expression, ITcon 11: 395408.

Ruikar, K.; Anumba, C. J.; Carrillo, P. M. 2003. Reengineering construction business processes through electronic commerce, The TQM Magazine 15(3): 197-212. http://dx.doi.org/10.1108/09544780310469343

Smith, D. K.; Tardif, M. 2009. Building Information Modeling: A Strategic Implementation Guide for Architects, Engineers, Constructors, and Real Estate Asset Managers. John Wiley \&Sons, Inc. 216 p.

Subramaniam, C.; Shaw, M. J. 2004. The effects of process characteristics on the value of B2B e-procurement, Information Technology and Management 5(1-2): 161-180. http://dx.doi.org/10.1023/B:ITEM.0000008080.17926.2b

Succar, B. 2009. Building information modeling framework: A research and delivery foundation for industry stakeholders, Automation in Construction 18(3): 357-375. http://dx.doi.org/10.1016/j.autcon.2008.10.003

Vonderembse, M. A.; Tracey, M. 1999. The impact of supplier selection criteria and supplier involvement on manufacturing performance, Journal of Supply Chain Management 35(3): 33-39. http://dx.doi.org/10.1111/j.1745-493X.1999.tb00060.x

Willis, T. H.; Huston, C. R.; Pohlkamp, F. 1993. Evaluation measures of just-in-time supplier performance, Production and Inventory Management Journal 34(2): 1-6.

Wu, T.; Blackhurst, J. 2009. Supplier evaluation and selection: an augmented DEA approach, International Journal of Production Research 47(16): 4593-4608. http://dx.doi.org/10.1080/00207540802054227

Zwass, V. 1996. Electronic commerce: structures and issues, International Journal of Electronic Commerce 1(1): 3-23.

Yali REN. Reliability Data Analyst Intern at Baker Hughes Inc. in Houston, TX, USA. She holds dual M.S. degrees in Civil Engineering from Tsinghua University, Beijing, China, and from the Univesity of Maryland, College Park, USA. Her research interests include IT and e-commerce solutions and applications in Civil Engineering and Project Management.

Mirosław J. SKIBNIEWSKI. Holder of A. James Clark Endowed Chair in Construction Engineering and Project Management at the University of Maryland (College Park), USA. A past winner of the Walter L. Huber Research Prize from the American Society of Civil Engineers and a foreign member of the Russian Academy of Engineering, he holds an honorary doctorate from Vilnius Gediminas Technical University in Lithuania. An author or coauthor of over 200 technical publications, he focuses his research on automation and information technology issues related to construction project engineering and management.

Shaohua JIANG. Assistant Professor in the Department of Construction Management, Faculty of Infrastructure Engineering, at Dalian University of Technology, China. His research interests include applications of long-distance tracking systems, building information and knowledge management, and project sustainability. 